\title{
Adjustment and Social Support of Pre-University College Adolescents
}

\author{
Dr. Maheshbabu. $\mathrm{N}^{1 *}$, Mr. Chandrkanth. B. $\mathrm{K}^{2}$, Dr. Shivakumar S Chengti ${ }^{3}$
}

\section{ABSTRACT}

The present study seeks to investigate the level of adjustment and social support of college going adolescents. Sample included 120 (simple random sampling method) randomly selected adolescents i.e. 60 boys and 60 girls college students from various pre-university colleges of Kalaburgi district of Hyderabad Karnataka. For obtaining the data on social support and adjustment, social support scale developed by Vaxu (1986), and adjustment inventory was developed by Sinha and Singh (1984) were used respectively. The statistical technique t-test and spearman rho coefficient of correlation was employed for comparing the two groups. The findings of the study showed that there exists significant difference in adjustment and social support between boys and girls. Whereas there exists no significant difference in respect to domicile between adjustment and social support. It also concludes that there exists positive and significant difference between adjustment and social support.

\section{Keywords: Adjustment, Social Support and Adolescents}

Adolescents throughout their college life are faced with a number of adjustment problems that could potentially affect their well-being. According to US department of health and human services (2003) found that 13 out of every 100 adolescents have experienced some kind of anxiety, stress and emotional imbalances and half of these students will be affected with a comorbid mental or behavioural disorder, such as depression. Given these concerns, research factors such as social support that may buffer adolescents from these poor outcomes is critical to determine potential interventions for these students. (Demaray \& Malecki, 2002a; Malecki \& Demaray, 2003; Piko, 2000; Wenz-Gross \& Siperstein, 1998) found that significant relationship between social support and adjustment of adolescents.

\footnotetext{
${ }^{1}$ Assistant Professor, Dept of PG Studies and Research in Psychology, Post Graduate Centre, Sri Dharmastala Manjunatheshwara College, SDM-Ujire, Dhakshin Kannada. Karnataka State, India

${ }^{2}$ Research Scholar, Dept of Psychology, Karnatak University Dharwad, Karnataka State, India

${ }^{3}$ Professor, Dept of Psychology, Gulbarga University Kalaburgi, Karnataka State, India

*Responding Author

Received: March 8, 2017; Revision Received: March 28, 2017; Accepted: March 30, 2017

(C) 2017 Maheshbabu N, Chandrkanth B, Chengti S; licensee IJIP. This is an Open Access Research distributed under the terms of the Creative Commons Attribution License (www.creativecommons.org/licenses/by/2.0), which permits unrestricted use, distribution, and reproduction in any Medium, provided the original work is properly cited.
} 


\section{Adjustment and Social Support of Pre-University College Adolescents}

Social support is an important factor in the development and maintenance of mental health. Social support was defined as an individual's perception that he or she is cared for, esteemed, and valued by people in his or her social network, that enhances personal functioning, assists in coping adequately with stressors, and may buffer him or her from adverse outcomes (Dubow, Tisak, Causey, Hryshko, \& Reid, 1991). Domitrovich and Bierman (2001) found that warm supportive parental practices were negatively related to aggression and positively related to prosocial behaviour. In addition, Dunn et al. (1987) and WenzGross et al. (1997) found family support to be related to college adjustment and academic self-concept.

Social support is one of the most important protective factors for adolescents (Tao et al., 2000). Social support includes social resources that individuals perceive to be available or that are actually offered to them by helping relationships (Cronkite \& Moos, 1995). Perceived social support is one of the most commonly used measures of social support. Perceived social support is a person's perception of the availability of support from others (i.e., friends and family) and captures the complex nature of social support including both the history of the relationship with the individual who provided the supportive behavior and the environmental context (Hobfoll \& Vaux, 1993). Barrera, Sandler, and Ramsay (1981) have proposed four different types of support that friends and family may offer including guidance and feedback (e.g., advice and instruction), non-directive support (e.g., trust and intimacy), positive social interactions (e.g., spending time with friends and family), and tangible assistance (e.g., shelter and money).

Adjustment is a state in which the needs of the individual on the one hand and the claims of the environment on the other are fully satisfied. Adjustment takes the form of variation of the environment and variation in the organism through the acquisition of responses appropriate to the situation. The variation in the organism may be biological. The adjustment process is a universal sequence that can be identified in the behaviour of organism from the lowest species up to man. Adjustment generally means an effective adaptation to the environment, both external and internal, including conformity to group norms, more ideals, values and so on (Abraham, 1968). According to Mouly ((1966) adjustment is the process by means of which an individual seems to maintain physiological equilibrium and propels himself toward self-enhancement. Whereas, Laycock (1946) grouped the problem of adolescents due to changing physical growth, physiological development, becoming emancipated from family and free from emotional dependence on parents. Parental unavailability, including lack of warmth, hostility, and rejection, has been linked to adolescents' internalizing problems such as depression, loneliness, distress, and somatic complaints, and to externalizing problems such as substance abuse, aggressiveness, and delinquent behavior (Conger, et al 1997; Campo \& Rohner, 1992; Crockenberg \& Leerkes, 2003; Rubin et al 2004). Adjustment therefore has been considered as an index to integration; a harmonious behavior of the individual by which other individuals of the society recognize the person as well adjusted (Pathak, 1990). Sajatha S., Caonkar V., Khadi P. and Katarhi P.A. (1993) have carried out their study in the Dharwad block of Karnataka state. They absorbed more on the 


\section{Adjustment and Social Support of Pre-University College Adolescents}

level of adjustments between male and female adolescents and found that male adolescents showed greater level of adjustment than the females. Therefore the present study is tries answering three questions. Do adolescents face problems in their social, emotional and educational aspects of life in respect to social support? What are the factors that influence their adjustment towards social life? Is there a gender difference between adjustment and social support of adolescent?

\section{Objectives}

1. To study the adjustment and social support of adolescent boys and girls.

2. To study the adjustment and social support of urban and rural adolescents.

3. To know the association between adjustment and social support of adolescent boys and girls students.

\section{Hypotheses}

1. There is significant difference in adjustment between boys and girls adolescents.

2. There is significant difference in social support between boys and girls adolescents.

3. There is significant difference in adjustment between urban and rural boys and girls students.

4. There is significant difference in social support between urban and rural boys and girls students.

5. There is significant association between adjustment and social support of adolescent girls students.

\section{METHODOLOGY}

\section{Sample}

One hundred and twenty (boys $n=60$ and girls $n=60$ ) adolescents studying in pre-university colleges of Kalaburgi district of Hyderabad Karnataka were selected to participate in this study. Their age ranged from 12 to 18 years and besides that domicile was taken into account. The simple random sampling method was followed.

\section{Procedure}

Present study is taken up to investigate the adjustment and social support in adolescent boys and girls, were studying in Pre-University colleges and suitable measuring instruments and structured questionnaires were administered following initial permission from the concerned authority and the participants were approached with mutual consent to fulfill the required measurements and questionnaires.

\section{Tools}

1. Adjustment inventory for school students (AISS): It was developed by Sinha and Singh (1984). It has 100 items with three areas namely: (a) Emotional adjustment: High 


\section{Adjustment and Social Support of Pre-University College Adolescents}

scores indicate unstable emotion. Students with low scores tend to be emotionally stable. (b) Social adjustment: Individuals scoring high are submissive and tiring. Low scores indicate aggressive behavior. (c) Educational adjustment: Individuals scoring high on third are poorly adjusted with their curricular and curricular programmes. Persons with low scores are interested in school/college programmes. The split-half reliability method was found to be .95 and validity was found to be .94 .

2. Perceived Social support scale developed by Vaxu et al. (1986). It consists of 23 items, self-report measure of the extent to which participants believe that they are valued by, and involved with, family members, friends, and others. Participants indicated the extent to which they endorsed statements about their social support (e.g., "I am loved dearly by my family" and "My friends don't care about my welfare") on a 4- point Likert scale from 1 (strongly disagree) to 4 (strongly agree). Three scores can be computed, including a family score (sum of 8 items assessing family support), a friend score (sum of 7 items assessing friendship support) and a general others score (the remaining 8 items assessing perceived support from "others” more generally; O’Reilly, 1995). Higher scores on eighteen of the items (items 1, 2, 4-9, 11, 12, 14-20, and 23) indicate higher levels of perceived social support, while higher scores on the other five items indicate lower levels of perceived social support. These latter five items will be reverse scored so that, in the overall analyses, higher scores will indicate higher levels of 30 perceived social support. The Social Support Appraisals Scale is correlated with other measures of perceived social support (O'Reilly, 1995), and previous studies have reported internal consistencies that range from 0.83-0.89 (O’Reilly, 1995; Vaux et al., 1986). The internal consistency for the Social Support Appraisals Scale in the current sample ranged from 0.92-0.94.

\section{Statistical techniques}

1. t-test

2. spearman rho coefficient of correlation

\section{RESULT AND DISCUSSION}

Table No 1. Shows mean SD and t-value of adjustment between boys and girls adolescents.

\begin{tabular}{|c|c|c|c|c|c|c|}
\hline \multirow{2}{*}{ Sl. No } & \multirow{2}{*}{ Adjustment } & \multicolumn{2}{|c|}{ Boys $n=60$} & \multicolumn{2}{|c|}{ Girls $n=60$} & \multirow{2}{*}{ t-value } \\
\hline & & Mean & SD & Mean & SD & \\
\hline 1 & Emotional adjustment & 51.82 & 10.56 & 48.18 & 9.12 & $2.02 *$ \\
\hline 2 & Social adjustment & 49.90 & 9.88 & 50.10 & 10.19 & $0.10 \mathrm{NS}$ \\
\hline 3 & Educational adjustment & 51.49 & 10.28 & 48.51 & 9.55 & $1.64 \mathrm{NS}$ \\
\hline & Overall adjustment & 51.96 & 10.29 & 48.04 & 9.37 & $2.18^{*}$ \\
\hline
\end{tabular}

NS: Not significant and Significant at *0.05 level 
Figure No 1. Shows sub-dimension \& overall adjustment mean scores of boys and girls adolescents.

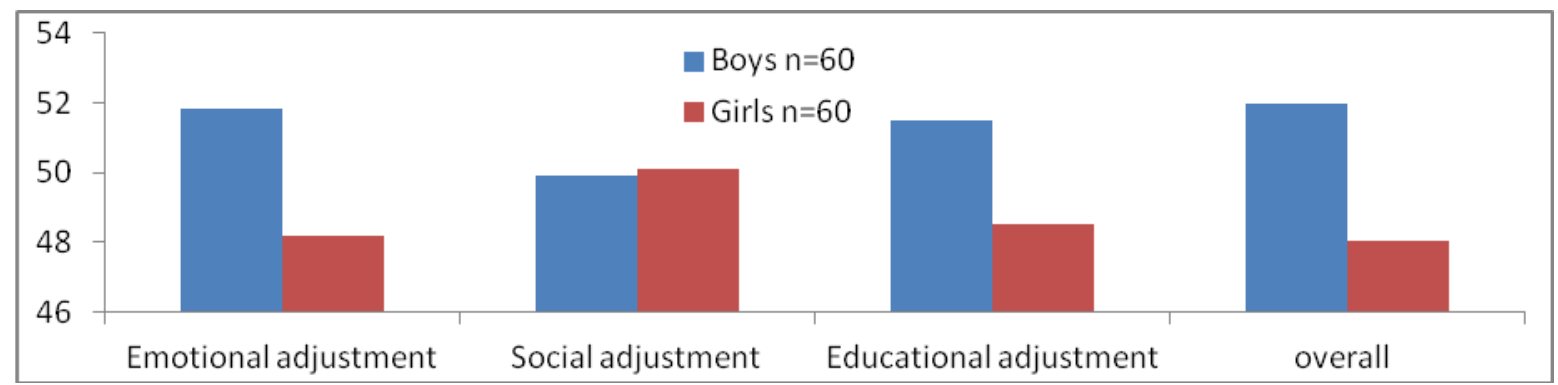

Table No 1 \& figure no 1, shows mean, SD and t-value of adjustment of boys and girls adolescents. The overall mean and SD score of boys is 51.96, 10.20 respectively, and the girls mean and SD score is 48.04, 9.37 respectively and the t-value is 2.18, which is significant at 0.05 level. Thus it suggests that boy adolescents have greater level of adjustment towards emotional adjustment. Hence, the first hypothesis, there is significant difference in adjustment between boys and girls, has been accepted.

The mean and SD scores of pregnant jobholders and homemakers in accordance with the dimensions of adjustments are: emotional adjustment (boys mean and SD scores of 51.82, 10.56 respectively and girls mean and SD scores of 48.18, 9.12 respectively. The t-value is 2.02, which is significant at 0.05 level). Whereas, social adjustment (boys mean and SD scores of 49.90, 9.88 respectively and girls mean and SD scores of 50.10, 10.19 respectively. The t-value is 0.10 , which is not significant at 0.05 level). Educational adjustment (boys mean and SD scores of 51.49, 10.28 respectively and girls mean and SD scores of 48.51, 9.55 respectively. The 1.64, which is not significant at 0.05 level). these results reveal that there exists no significant difference between the scores of social adjustment and educational adjustment dimensions of boys and girls adolescents whereas the scores of emotional adjustment reveals that there exists significant difference in level of emotional adjustment between boys and girls. Similar findings were reported by Srivastava et al. (2012); Sharon and Miller (1998) \& Irshad and Tali (2014) who concluded that boys exhibited greater level of adjustment in comparison to girls. It also noted that though boys are significantly better adjusted than girls, their level of adjustment is average.

Table No 2, shows mean SD and t-value of adjustment between boys and girls adolescents.

\begin{tabular}{|l|l|l|l|l|l|l|}
\hline \multirow{2}{*}{ Sl. No } & \multirow{2}{*}{ Social support } & \multicolumn{2}{|l|}{ Boys $\boldsymbol{n}=\mathbf{6 0}$} & \multicolumn{2}{l|}{ Girls $\boldsymbol{n}=\mathbf{6 0}$} & \multirow{2}{*}{ t-value } \\
\cline { 3 - 6 } & & Mean & SD & Mean & SD & \\
\hline 1 & Family support & 50.64 & 8.42 & 49.36 & 11.39 & 0.70 NS \\
\hline 2 & Friendship support & 54.10 & 6.78 & 45.90 & 11.02 & $4.90^{* * *}$ \\
\hline 3 & Others & 52.37 & 8.74 & 47.63 & 10.66 & $2.65^{* *}$ \\
\hline \multicolumn{2}{|l}{ Overall social support } & 54.82 & 9.23 & 45.18 & 8.32 & $6.00^{* * *}$ \\
\hline
\end{tabular}

NS: Not significant, Significant at $* * 0.01$ and $* * * 0.001$ levels

(C) The International Journal of Indian Psychology, ISSN 2348-5396 (e) | ISSN: 2349-3429 (p) | 82 
Figure No 2. Shows sub-dimension \& overall social support mean scores of boys and girls adolescents.

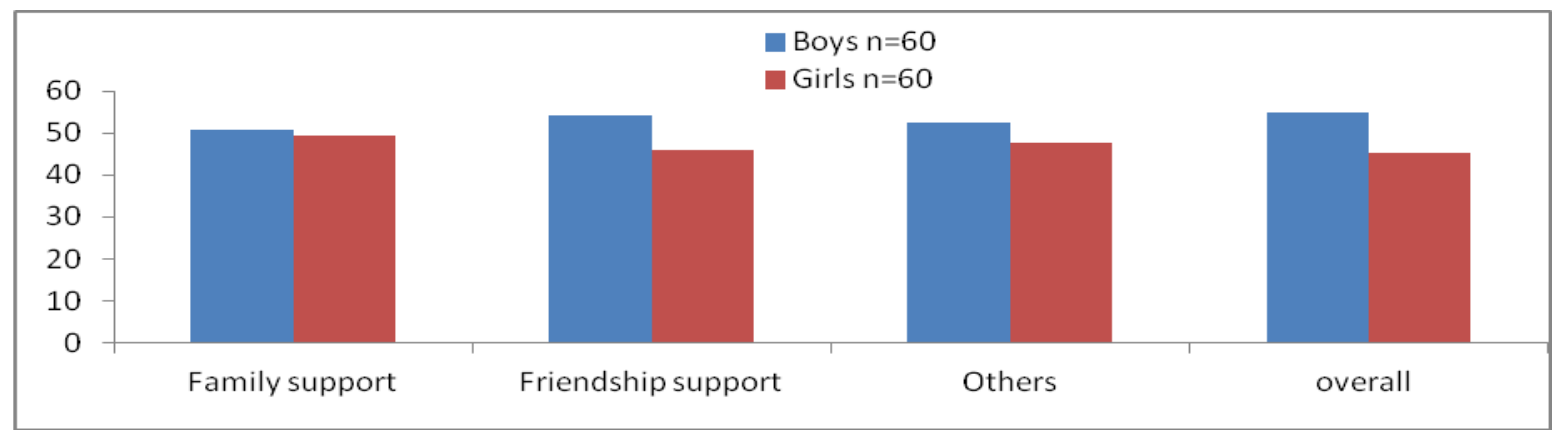

Table no 2 \& figure no 2, illustrates that overall social support and its dimensions scores of the boy and girl adolescents. The result revealed that the boys have higher mean and SD scores of 54.82, 9.23 respectively, and the girls have lower mean and SD scores of 45.18, 8.32 respectively. The t-value is 6.00 , which is significant at 0.001 level. The result shows that there is significant difference in overall social support between boy and girl adolescents. Thus the mean scores suggest that boys have greater social support as compared to girls. Hence the second hypothesis, there is significant difference in social support between boys and girls adolescents, has been accepted.

The mean and SD scores of boys and girls adolescents in accordance with the dimensions of social support are friendship support dimension boys mean and SD scores of 54.10, 6.78 respectively and girls mean and SD scores of 45.90, 11.02 respectively. The t-value is 4.90, which is significant at 0.001 level. the social support dimension of 'others' the boys mean and SD scores of 52.37, 8.74 respectively and girls mean and SD scores of 47.63, 10.66 respectively. The t-value is 2.65 , which is significant 0.01 level. These results reveal significant difference in the above stated dimensions of social support in boys and girls adolescents.

Whereas, family support dimension of boys mean and SD scores of 50.64, 8.42 respectively, and the girls mean and SD scores of 49.36, 11.39 respectively. The t-value is 0.70 , which is not significant at 0.05 level. This result reveals that there is no significant difference found in boys and girls adolescents in respect to the above stated dimension.

Similar results were reported by Mahanta and Megha (2013); Holahan, et.al. (1995); Davis (1998) who reported that no gender differences in social support from family but a significant difference was found out for the perceived social support from friends and others as well. Whereas, Bolhari and et al, and Hooman (1995). Indicated that girls have more social support than boys. 
Table No 3. Shows mean SD and t-value of adjustment between urban and rural adolescents.

\begin{tabular}{|l|l|l|l|l|l|}
\hline \multirow{2}{*}{} & \multicolumn{2}{|l|}{ Urban $\boldsymbol{n}=\mathbf{6 3}$} & \multicolumn{2}{l|}{ Rural $\boldsymbol{n}=\mathbf{5 7}$} & \multirow{2}{*}{ t-value } \\
\cline { 2 - 6 } & Mean & SD & Mean & SD & \\
\hline Adjustment & 50.53 & 10.79 & 49.42 & 9.10 & 0.60 NS \\
\hline
\end{tabular}

NS: Not significant

Figure No 3. Shows adjustment mean scores of urban and rural adolescents.

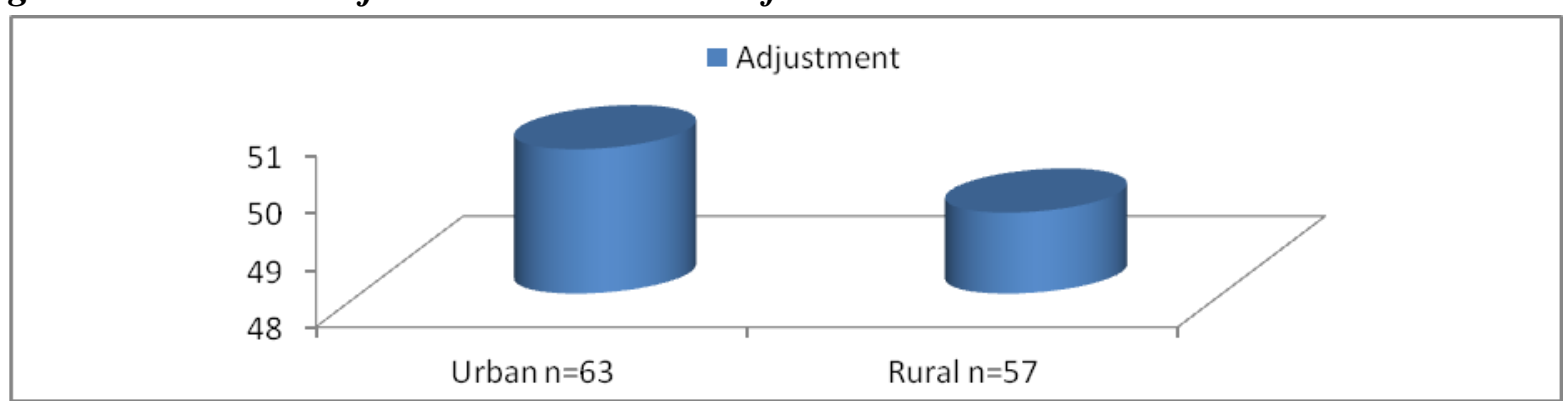

The above table no 3 \& figure no 3 illustrates adjustment scores of urban and rural adolescents. The scores of adjustment of urban and rural adolescents mean and SD scores of 50.53, 10.79 respectively and 49.42, 9.10 respectively. The t-value is 0.60 , which is not significant at 0.05 level. Thus it indicates that there is no significant difference in adjustment between urban and rural adolescents. Hence the third hypothesis, there is significant difference in adjustment between urban and rural adolescents, has been rejected.

Table No 4. Shows mean SD and t-value of social support between urban and rural adolescents.

\begin{tabular}{|l|l|l|l|l|l|}
\hline \multirow{2}{*}{} & \multicolumn{2}{|l|}{ Urban $\boldsymbol{n}=\mathbf{6 3}$} & \multicolumn{2}{l|}{ Rural $\boldsymbol{n}=5 \mathbf{7}$} & \multirow{2}{*}{ t-value } \\
\cline { 2 - 6 } & Mean & SD & Mean & SD & \\
\hline Social support & 50.19 & 9.96 & 49.79 & 10.12 & 0.21 NS \\
\hline
\end{tabular}

NS: Not significant

Figure No 4. Shows social support mean scores of urban and rural adolescents.

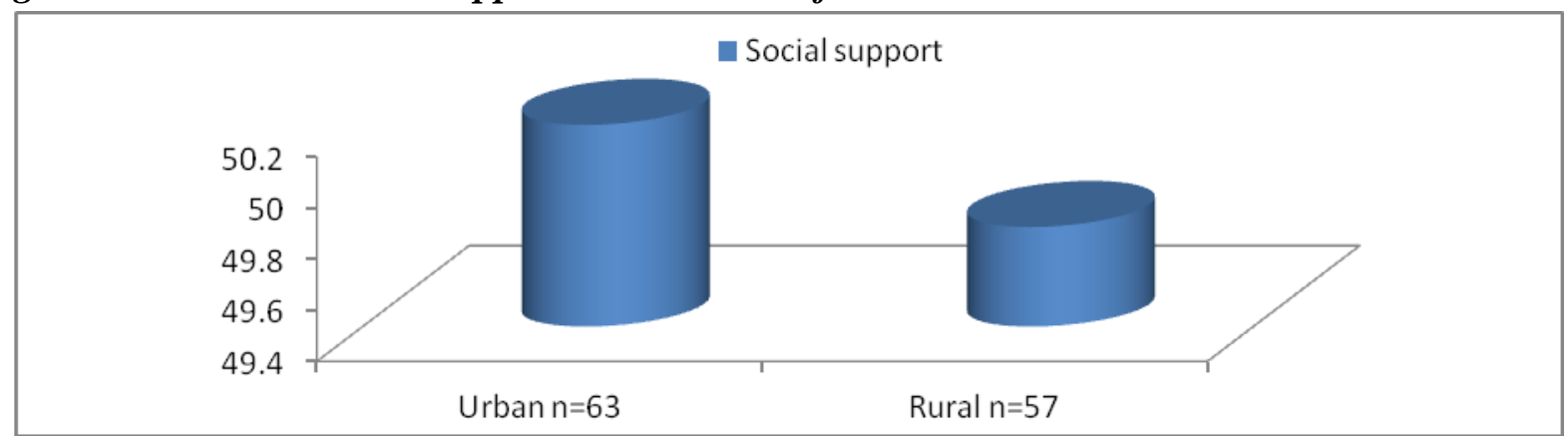

Table no 4 and figure no 4 shows social support scores of the urban and rural adolescents. The results revealed that urban adolescents mean and SD scores of 50.19, 9.96 respectively and the rural adolescents mean and SD scores of 49.79, 10.12 respectively. The t-value is 0.21 , which is

(C) The International Journal of Indian Psychology, ISSN 2348-5396 (e)| ISSN: 2349-3429 (p) | 84 


\section{Adjustment and Social Support of Pre-University College Adolescents}

not significant at 0.05 level. Thus, the result shows there is no significant difference in social support between urban and rural adolescents. Though the mean scores indicates that urban adolescents exhibited slightly better social support in comparison to rural adolescents. Hence, the fourth hypothesis, there is significant difference in social support between urban and rural adolescents, has been rejected.

Table No 5: Shows correlation between adjustment and social support of adolescents.

\begin{tabular}{|l|l|}
\hline Variable & $\mathbf{r}=$ value \\
\hline Adjustment \& social support & $.226^{* *}$ \\
\hline
\end{tabular}

Significant at $* * 0.01$ level

Table no 5 depict that coefficient of correlation between adjustment and social support of adolescents. The correlation value is $.226^{* *}$, which is significant at 0.01 level. Thus it is indicated that there is significant correlation between adjustment and social support of adolescents. It suggests that better the adjustment increases the level of social support of adolescents. Hence the fifth hypothesis: there is positive and significant correlation between adjustment and social support has been accepted.

\section{FINDINGS AND SUGGESTIONS}

The major findings of the study are that;

1. Firstly, there is significant difference in the level of adjustment between boys and girls. It indicates that the boys exhibited greater adjustment in terms of emotional, social and educational adjustment.

2. Secondly, there exists significant difference in overall social support between boys and girls. It indicates that the boys showed higher level of social support in terms of friends and others supports in comparison to girls. Whereas no significant difference is found in family support between boys and girls.

3. Thirdly, there is no significant difference in the level of adjustment between urban and rural adolescents.

4. Fourthly, there is no significant difference in the level of social support between urban and rural adolescents.

5. Further, it is also concluded that there exists positive and significant difference between adjustment and social support.

\section{CONCLUSIONS}

Based on the findings of the present study this paper confirms that the boys were showed better adjustment and greater level of social support from friends, peer groups and society as compared to girls and study also concludes that irrespective of the nature of environment in adolescents whether urban or rural adolescents, the levels of adjustment and social support does not change and there exists positive and significant correlation between adjustment and social support of

(C) The International Journal of Indian Psychology, ISSN 2348-5396 (e)| ISSN: 2349-3429 (p) | 85 


\section{Adjustment and Social Support of Pre-University College Adolescents}

boys and girls adolescents. This field being new and emerging, future work should be taken up to clarify the relationship between the variables

\section{Acknowledgments}

The author appreciates all those who participated in the study and helped to facilitate the research process.

Conflict of Interests: The author declared no conflict of interests.

\section{REFERENCES}

Bagheri Yazdi A, Bolhari G, Peiravi H.(1995). Assessing mental health student in Tehran University academic year 1994-1995. Thought and Behavior J. 1(4): 85-90

Campo, A. T., \& Rohner, R. P. (1992). Relationship between perceived parental acceptance rejection, psychological adjustment and substance abuse. Child Abuse \& Neglect, Vol. 16, pp. 429-440.

Conger, K.J., Conger, R.D. and Scaramella, L.V., (1997), Parents, siblings, psychological control and adolescent adjustment. Journal of Adolescent Research, 12(1) : 113-138.

Crockenberg, S. C., \& Leerkes, E. M. (2003). Parental acceptance, postpartum depression, and maternal sensitivity: Mediating and moderating processes. Journal of Family Psychology, Vol. 17, pp. 80-93.

Davis, S. L. (1998). "Social and scientific influences on the study of children's suggestibility: A historical perspective.” Child Maltreatment 3: 186-194.

Demaray, M.K., \& Malecki, C.K. (2002). Critical levels of perceived social support associated with student adjustment. School Psychology Quarterly, 17, 213-241.

Dimpy Mahanta Megha Aggarwal (2013). Effect of Perceived Social Support on Life Satisfaction of University Students. European academic research, vol. I, ISSUE 6.

Dubow, E.F., Tisak, J., Causey, D., Hryshko,A., \& Reid, G. (1991).Atwo-year longitudinal study of stressful life events, social support, and social problem-solving skills: Contributions to children's behavioral and academic adjustment. Child Development, 62, 583-599.

Holahan, C.J., Valentiner, D.P., \& Moos, R.H. (1995). “Parental Support, coping strategies and psychological adjustment: An integrative model with late adolescents.” Journal of Youth and Adolescence 24(6): 663-648.

Irshad Ali Dar \& Latief Ahmad Tali (2014). Adjustment Problems among Kashmiri Adolescents. international journal of English language, literature and humanities. Volume 1 Issue V Feb 2014

Laycock, S. R. (1946). How Parents hinder Adolescents Adjustment to the Opposite sex. Journal of school health, Vol. 16, No. 6, pp. 151-156.

Malecki, C.K., \& Demaray, M.K. (2003). What type of support do they need? Investigating student adjustment as related to emotional, informational, appraisal, and instrumental support. School Psychology Quarterly, 18, 231-252. 


\section{Adjustment and Social Support of Pre-University College Adolescents}

Paikoff, R. L., \& Brooks-Gunn, J. (1991). Do parent- child relationships change during puberty? Psychological Bulletin, 110, 47-66

Piko, B. (2000). Perceived social support from parents and peers: Which is the stronger predictor of adolescent substance use? Substance Use \& Misuse, 35, 617-631.

Rubin, K. H., Dwyer, K. M., Booth, L. C., Kim, A. H., Burgess, K. B., \& Rose, K. L. (2004). Attachment, friendship, and psychosocial functioning in early adolescence. Journal of Early Adolescence, Vol. 24, pp. 326-356

Sharon Marine, PhD, and Deborah Miller, (1998). Social Support, Social Conflict, and Adjustment Among Adolescents With Cancer. Journal of Pediatric Psychology, Vol. 23, No. 2, 1998, pp. 121-130

Sinha, A.K. \& Singh, R.P. (1984). Manual for adjustment inventory for school students/college (AISS). Agra: National psychological corporation.

Srivastava, S.K.; Barmola, Kailash Chandra (2012). Social Support and Adjustment of Students. Social Science International, Vol. 28 Issue 2, p303-317. 15p

U.S. Department of Health and Human Services, Substance Abuse and Mental Health Services Administration. (2003). National Mental Health Information Center. Retrieved December 19, 2003, from http://www.mentalhealth.samhsa. gov/publications/browse.asp

Vaux, A., Phillips, J., Holly, L., Thomson, B., Williams, D., \& Stewart, D. (1986). The social support appraisals (SS-A) scale: Studies of reliability and validity. American Journal of Community Psychology, 14(2), 195-218.

Wenz-Gross, M., \& Siperstein, G.N. (1998). Students with learning problems at risk in middle school: Stress, social support, and adjustment. Exceptional Children, 65, 91-100.

How to cite this article: Maheshbabu N, Chandrkanth B, Chengti S (2017), Adjustment and Social Support of Pre-University College Adolescents, International Journal of Indian Psychology, Volume 4, Issue 2, No. 96, ISSN:2348-5396 (e), ISSN:2349-3429 (p), DIP:18.01.188/20170402, ISBN:978-1-365-84232-0 